\title{
Modeling the saltwater intrusion in the lowlying catchment of the southern Venice Lagoon, Italy
}

\author{
P. Teatini ${ }^{1}$, M. Putti ${ }^{1}$, C. Rorai $^{1}$, A. Mazzia ${ }^{1}$, G. Gambolati ${ }^{1}$, \\ L. Tosi ${ }^{2} \&$ L. Carbognin ${ }^{2}$ \\ ${ }^{1}$ Department of Mathematical Methods and Models for Scientific \\ Applications, University of Padova, Italy \\ ${ }^{2}$ Institute of Marine Sciences, National Research Council, Venice, Italy
}

\begin{abstract}
The coastland surrounding the southern Venice Lagoon, Italy, is a precarious environment subject to both natural changes and anthropogenic pressure. One major environmental problem is the saltwater intrusion in shallow aquifers. The salt contamination is generally the result of seawater encroachment, but significant contributions can also be due to the water exchange between the bed of the major rivers and the subsurface. In fact, the reduced freshwater discharges that occur in the Brenta and Bacchiglione rivers during the dry periods allow the saltwater to flow up from the river mouths for several kilometres. Saltwater intrusion is enhanced by a land elevation well below the mean sea level and by the presence of several ancient sandy fluvial ridges and buried paleo-channels, crossing the farmland with a main direction from inland to the lagoon boundary, that can act as preferential pathways for groundwater flow and solute transport. Using as input data a geological, geophysical, hydrological data set collected around the Casetta pumping station over 2004-2005, a numerical model has been developed to investigate the saltwater intrusion process along the margin of the southern Venice Lagoon. The model solves the coupled density dependent flow and transport equations by a highly accurate numerical approach based on the mixed hybrid finite element (MHFE) method and a combination of MHFE with high resolution finite volumes (HRFV) for the discretization of the flow and transport equations, respectively. A set of simulations has been initially carried out to analyze the effect of the natural factors forcing the saltwater intrusion in the coastal aquifer system. Preliminary results provide evidence of the strong
\end{abstract}


influence exerted by the river freshwater that can represent an effective hydraulic barrier to salt contamination from the lagoon. By contrast the river can be a strong source of salinization for the phreatic aquifer if seawater encroaches along the final $15-20 \mathrm{~km}$ of the watercourses.

Keywords: saltwater intrusion, desertification, Venice coastland.

\section{Introduction}

Groundwater/seawater exchange in coastal areas impacts both onshore and offshore the quality of water resources through saltwater intrusion into watersupply aquifers and the discharge of contaminated groundwater into the coastal sea. Saltwater intrusion represents a threat to drinking water quality [1], enhances the risk of soil desertification [2], compromises the agricultural practices [3], and diminishes freshwater storage capacity. Meanwhile, submarine groundwater discharge can transport significant chemical loads to the sea [4] that can affect coastal ecological systems [5]. Water and chemical fluxes across the land/sea margin are thus important from both a human and an environmental health perspective, and an understanding of the geophysical and geological processes controlling flow dynamics in coastal aquifers is a worthwhile endeavour.

The coastland surrounding the southern Venice Lagoon, Italy (fig. 1a), is a precarious environment subject to both natural changes and anthropogenic pressure. A number of critical issues affect this lowlying area, i.e. relative land subsidence, periodic flooding during severe winter storms, and saltwater intrusion. The combined effect of sea level rise and land subsidence has enhanced the saltwater contamination and the related soil salinization with serious environmental and socio-economic consequences. A preliminary study, i.e. the ISES Project (ISES is the Italian acronym for Saltwater Intrusion and Land Subsidence), was undertaken in 2000 to identify areas and depths involved by saltwater pollution. A network was established to monitor the water quality with the analyses and the geophysical investigations showing that the saline water may extend inshore up to $20 \mathrm{~km}$ far from the Adriatic Sea coastline and the contaminant plume may propagate from near ground surface down to $100 \mathrm{~m}$ in some areas [6].

Based on the ISES outcome, an experimental program has been carried out in the framework of the 2004-2006 Research Program of Co.Ri.La. (Consortium for Coordination of Research Activities concerning the Venice Lagoon System) to evaluate the groundwater exchange between the southern part of the Venice Lagoon and the surrounding farmland with the aid of time lapse electrical resistivity tomography (TL-ERT). The measurements point to the wide extent of the contamination at the Casetta test site and provide evidence of the complexity of the relationship between groundwater quality and a number of environmental factors such as the sea water level in the nearby lagoon, the river fresh/salt water seepage, the freshwater recharge from rainfall, the drainage activities implemented to keep dry the farmland $[7,8]$. 

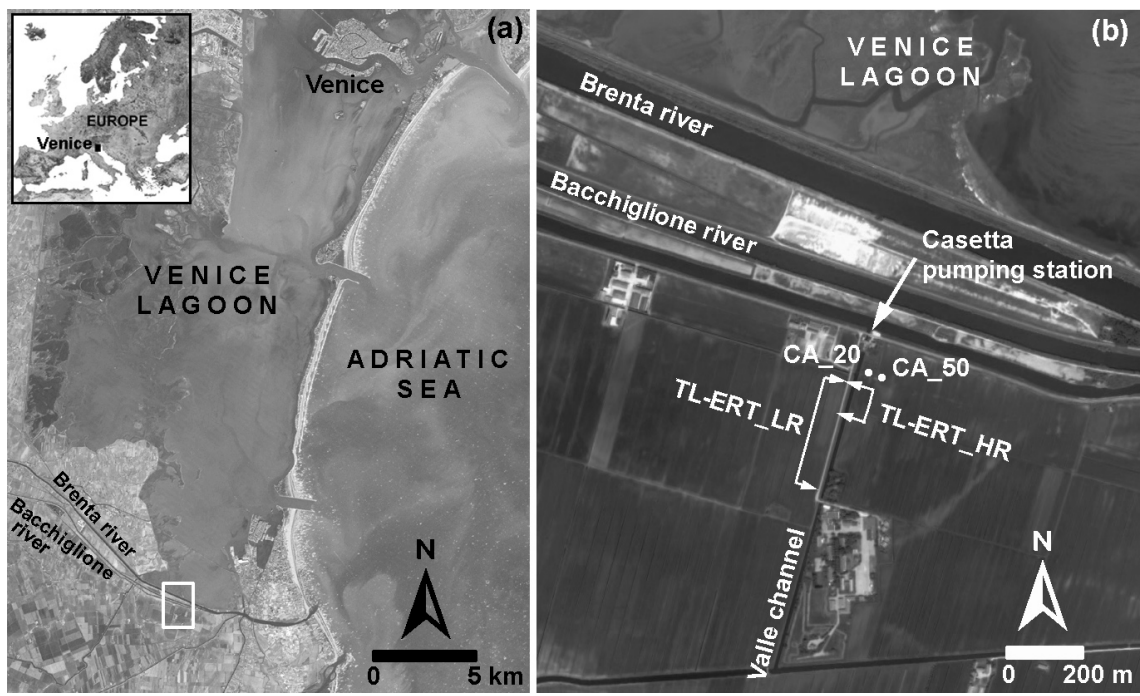

Figure 1: (a) Map of the southern part of the Venice Lagoon with the location of the Casetta area (white box). (b) The Casetta area with the trace of the TL-ERT experiments and the boreholes used to characterize the subsurface stratigraphy and constrain the interpretation of the geophysical surveys.

The present communication reports on the preliminary results from a modeling study undertaken for the Casetta site (fig. 1(a)), focusing in particular on the role exerted by a few surface water bodies, i.e. the lagoon and the Brenta and Bacchiglione rivers, on the mechanism of saltwater contamination of the phreatic and shallow semi-confined aquifers at the southern boundary of the Venice Lagoon. Salt is nonreactive, and hence it is not as complex to model as other components which undergo chemical/biological transformations in soils. On the other hand, the presence of salt alters water density in such a way as to induce important effects on the pore pressure and flow fields and thereby on the dynamics of the system, with these effects raising a number of mathematical and numerical difficulties. A proper simulation of so-called density-dependent phenomena in groundwater flow and transport relies on coupled models that incorporate the constitutive relationship between solute concentration and density.

\section{The Casetta study site and the use of TL-ERT to monitor the saltwater dynamics}

The study site is located about $500 \mathrm{~m}$ south of the Venice Lagoon edge and close to the Casetta pumping station, one of the hydraulic structures managed by the Adige-Bacchiglione Reclamation Authority to drain the lowlying farmland bounding the southern lagoon portion. The Brenta and Bacchiglione rivers flow 


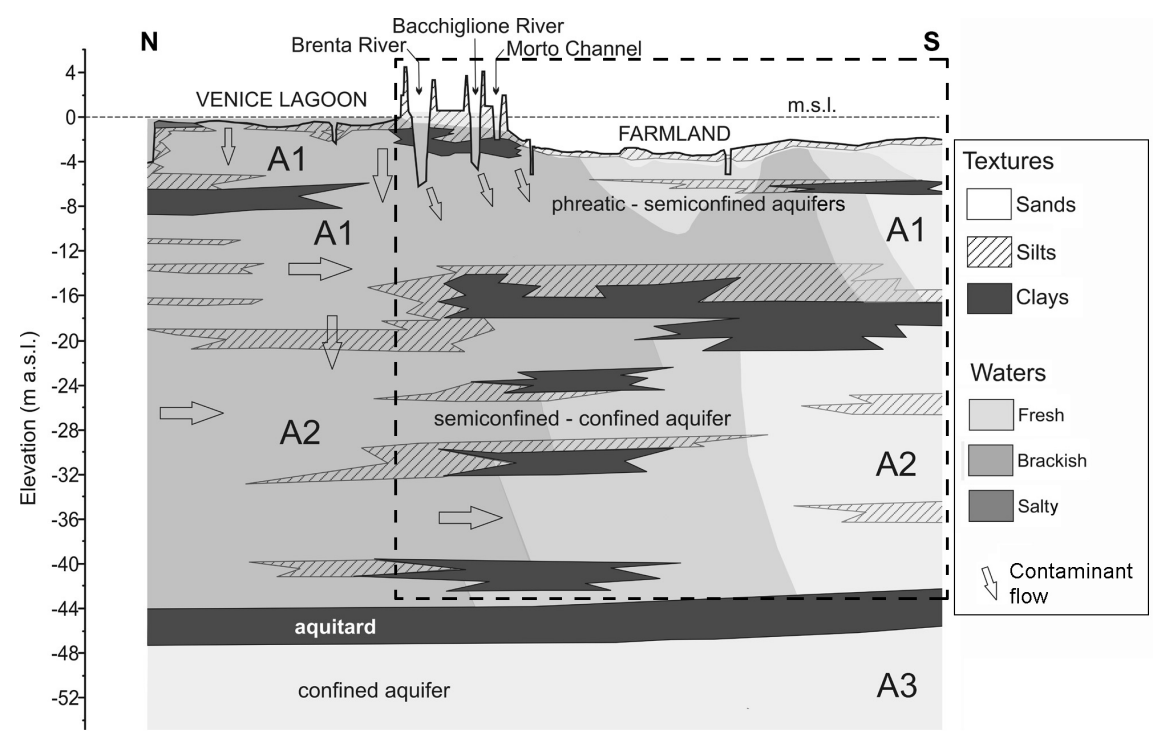

Figure 2: Hydrogeological conceptual model of the study area as obtained from the integration of the overall information collected during the TL-ERT experiment. The vertical section is parallel to the ERT tomography and extends northward below the lagoon bottom. The box between the dashed vertical lines represents the domain simulated with the numerical model. Vertical exaggeration is 50 .

within the strip included between the test area and the lagoon. The Casetta pumping station drains off the surplus water collected by the Valle channel (fig. 1(b)).

The investigated subsurface is the upper $60 \mathrm{~m}$ of the regional multi-aquifer system underlying the overall Venice plain and composed of a few aquifers. The system consists of phreatic and locally confined aquifers down to about $70 \mathrm{~m}$ with a complex architecture resulting from a series of heteropic processes involving alluvial, lagoon, deltaic, and littoral deposits. The permeability values show lateral and vertical variability due to the high textural heterogeneity of the deposits varying from $10^{-3}$ to $10^{-7} \mathrm{~m} / \mathrm{s}$ and from $10^{-7}$ to $10^{-11} \mathrm{~m} / \mathrm{s}$ for the aquifers and aquitards, respectively [9]. In order to obtain the local stratigraphy and constrain the geoelectrical interpretation, two $20 \mathrm{~m}$ and $50 \mathrm{~m}$ deep boreholes (CA_20 and CA_50, respectively, fig. 1(b)) were drilled in the area. The stratigraphy thus obtained (fig. 2) suggests the presence of a shallow phreatic aquifer (A1) down to $12 \mathrm{~m}$, followed by a semi-confined (A2) aquifer between 18 and $38 \mathrm{~m}$ depth and a locally confined aquifer (A3) down to the $70 \mathrm{~m}$.

One major environmental issue in this portion of the Venice coastland is the aquifer contamination by salty water that seriously affects the agricultural activities. With reference to the tolerance limits typically used in agriculture of the study area and to the properties of the sands that are rich in silt components, brackish water with an electrical conductivity larger than $2 \mathrm{mS} / \mathrm{cm}$, i.e., a salt 
concentration higher than 1-2 gr/l, is unsuitable for irrigation purposes. The seawater intrusion is enhanced by a land elevation well below the mean sea level (down to $-3.5 \mathrm{~m}$ ) and the presence of several sandy paleo-channels crossing the farmland with a main direction from inland to the lagoon boundary $[6,9]$ that can act as preferential pathways for groundwater flow and solute transport. The salinization dynamics in the shallow subsoil is especially sensitive to the variations in the freshwater river discharge, the hydrometric levels in the drainage channels maintained by the pumping stations, and the climatic conditions. The former is influenced by the tide dynamics which, together with river flow, control the seawater encroachment along the river mouths.

The dynamics of saltwater intrusion along a profile perpendicular to the lagoon margin has been studied by an electrical time lapse resistivity tomography (TL-ERT) experiment. This was carried out by means of an apparatus implemented for this purpose and capable to acquire ten electrotomographies per day over about one year starting from November 2005: five tomographies down to a $15-20 \mathrm{~m}$ depth are acquired at a high resolution by a $97.5 \mathrm{~m}$ long and $2.5 \mathrm{~m}$ electrode spacing ERT line (TL-ERT_HR), and five by a $300 \mathrm{~m}$ long and $5 \mathrm{~m}$ electrode spacing line that allow for the investigation to reach a 50-60 m depth (TL-ERT_LR) [7].

The seasonal oscillations of the contamination level are clearly distinguishable in the resistivity model as it is shown in fig. 3 where two representative tomographic sections obtained by data inversion from November and May are presented for the TL-ERT_LR line. With the exception of the upper 2-4 $\mathrm{m}$, the contamination reached the maximum inshore extent from the lagoon margin during the wet season in contrast to the general behaviour observed in other coastal sites governed by temperate climate. This occurrence is likely to be due to the superposition of the pumping station activities, which keep the lowest groundwater levels in the winter to minimize the risk of lowland flooding, spring/summer irrigation and deep fresh groundwater supply from the mainland, and the seasonal lagoon water levels that usually reach the maximum values from November to March. The resistivity changes in the first confined aquifer (fig. 3) are probably due to an increased fresh water recharge coming from mainland at regional scale.

\section{Modeling the saltwater intrusion}

\subsection{The mathematical model}

The mathematical model of density-dependent flow in porous media can be expressed in terms of an equivalent freshwater head $h$ defined as $h=\psi+z$, where $\psi=p /\left(\rho_{0} g\right)$ is the equivalent freshwater pressure head, $p$ is the pore pressure, $\rho_{0}$ is the freshwater density, $g$ is the gravitational constant, and $z$ is the vertical coordinate directed upward.

The density $\rho$ of the saltwater solution is written in terms of the reference density $\rho_{0}$ and the normalized (actual divided by maximum) salt concentration $c$ :

$$
\rho=\rho_{0}(1+\varepsilon c)
$$




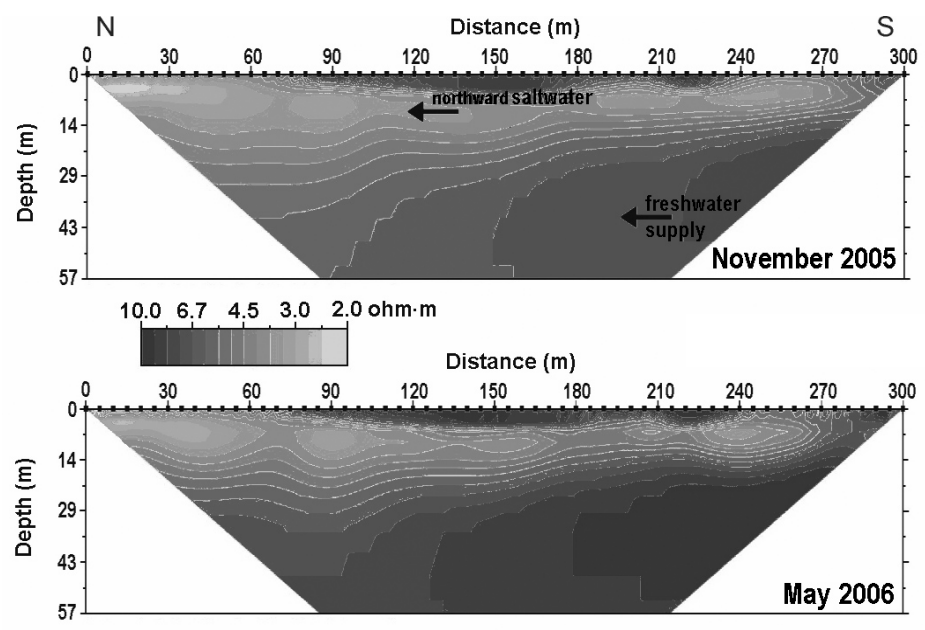

Figure 3: Resistivity models showing the evolution of saltwater intrusion between November and May for the low resolution TL-ETR line (after [7]).

where $\varepsilon=\left(\rho_{\mathrm{s}}-\rho_{0}\right) / \rho_{0}$ is the density ratio, typically equal to $0.025-0.030$ for oceans and open seas, and $\rho_{\mathrm{s}}$ is the density of the solution at $c=1$. The dynamic viscosity $\mu$ of the saltwater mixture is also expressed as a function of $c$ and the reference viscosity $\mu_{0}$ as:

$$
\mu=\mu_{0}\left(1+\varepsilon^{\prime} c\right)
$$

where $\varepsilon=\left(\mu_{\mathrm{s}}-\mu_{0}\right) / \mu_{0}$ is the viscosity ratio and $\mu_{\mathrm{s}}$ is the solution viscosity at $c=1$.

With the above definitions, the mass conservation equations for the coupled flow and transport model in porous media can be written, in terms of the unknown pressure head $\psi$ and normalized concentration $c$, as [10]:

$$
\begin{gathered}
\sigma \frac{\partial \psi}{\partial t}=\vec{\nabla} \cdot\left[K_{s} \frac{1+\varepsilon c}{1+\varepsilon^{\prime} c} K_{r}\left(\vec{\nabla} \psi+(1+\varepsilon c) \eta_{z}\right)\right]-\phi S_{w} \varepsilon \frac{\partial c}{\partial t}+\frac{\rho}{\rho_{0}} q^{*}+q \\
\vec{v}=-K_{s} \frac{1+\varepsilon c}{1+\varepsilon^{\prime} c} K_{r}\left(\vec{\nabla} \psi+(1+\varepsilon c) \eta_{z}\right) \\
\phi \frac{\partial S_{w} c}{\partial t}=\vec{\nabla} \cdot(D \vec{\nabla} c)-\vec{\nabla} \cdot(c \vec{v})+q c^{*}+f
\end{gathered}
$$

where $t$ is time, $\sigma=S_{w} S_{s}(1+\varepsilon c)+\not(1+\varepsilon c) \mathrm{d} S_{w} / \mathrm{d} \psi$ is the general storage term with $S_{s}$ the storage coefficient, $S_{w}=\theta / \theta_{s}$ with $\theta$ the volumetric soil moisture content and $\theta_{s}$ the saturated moisture content, $\phi$ is the porosity of the medium, $K_{s}$ is the hydraulic conductivity tensor at the reference density, $K_{r}$ is the relative hydraulic conductivity, $\eta_{z}$ is a vector equal to zero in its $x$ and $y$ components and 1 in its $z$ component, $q^{*}$ is the injected and $q$ the extracted volumetric flow rate, $\vec{v}$ is the Darcy velocity vector, $D$ is the dispersion tensor given by 
$D=\left(\phi D_{0}+\alpha_{T}|\vec{v}|\right) I+\left(\alpha_{L}-\alpha_{T}\right) \vec{v} \cdot \vec{v}^{T} /|\vec{v}|$, with $D_{0}$ the molecular diffusion coefficient and $\alpha_{L}$ and $\alpha_{T}$ the longitudinal and transverse dispersivity coefficients, $c^{*}$ is the normalized concentration of salt in the injected/extracted fluid, and $f$ is the volumetric rate of injected (positive)/extracted (negative) solute that does not affect the velocity field.

Appropriate initial and Dirichlet, Neumann, or Cauchy boundary conditions, and empirical relationships describing the pressure head dependencies of the relative hydraulic conductivity for the case of variably saturated flow are added to complete the mathematical formulation of the coupled flow and transport problem.

\subsection{The numerical model}

A combination of the mixed hybrid finite element (MHFE) and a high resolution finite volumes (HRFV) methods with the time splitting technique is implemented to solve eqs. (3)-(5). These numerical schemes guarantee an accurate and reliable solutions for both the velocity and the concentration field also where the transport equation is advection dominated or the flow is orthogonal to the concentration gradient, in which case the amount of transverse dispersion is responsible for the high nonlinearities and large local Courant-Friedrichs-Lewy $(\mathrm{CFL})$ and Peclet $(\mathrm{Pe})$ numbers that pose challenges to the numerical scheme $[11,12]$.

The MHFE formulation is used for the discretization of the flow equation along with a weighted scheme for integration in time. The time-splitting technique applied to the transport equation solves separately advection and dispersion by combining a cell-centered HRFV and a MHFE scheme for the advective and dispersive equations, respectively, with the integration in time that is explicit for the HRFV scheme and implicit for the MHFE method. Stability of the explicit advection discretization is determined by the CFL constraint, while the dispersive step is not subject to stability restrictions. Therefore different time steps are used for advection and dispersion, with a smaller advection time step together with a coarser dispersive time step implemented.

The numerical scheme has been used with the COUP_HYB fortran simulator $[11,12]$. The solution to the discretized system of equations is addressed with an iterative Picard-like scheme by which the problem is decoupled by first solving the flow equation, then calculating the velocity field, and finally solving the transport equation. This three-step sequence is repeated until convergence

\section{Model application on the Venice coastland}

\subsection{Model set-up}

COUP_HYB has been applied to simulate the saltwater intrusion along the north-south vertical section that runs parallel to the ERT lines from the lagoon boundary and the watercourses to the inner farmland.

The model domain, highlighted by a dashed box in the hydrogeological section of fig. 2 and sketched in fig. 4 , is about $1000 \mathrm{~m}$ long and $30 \mathrm{~m}$ deep, i.e. 


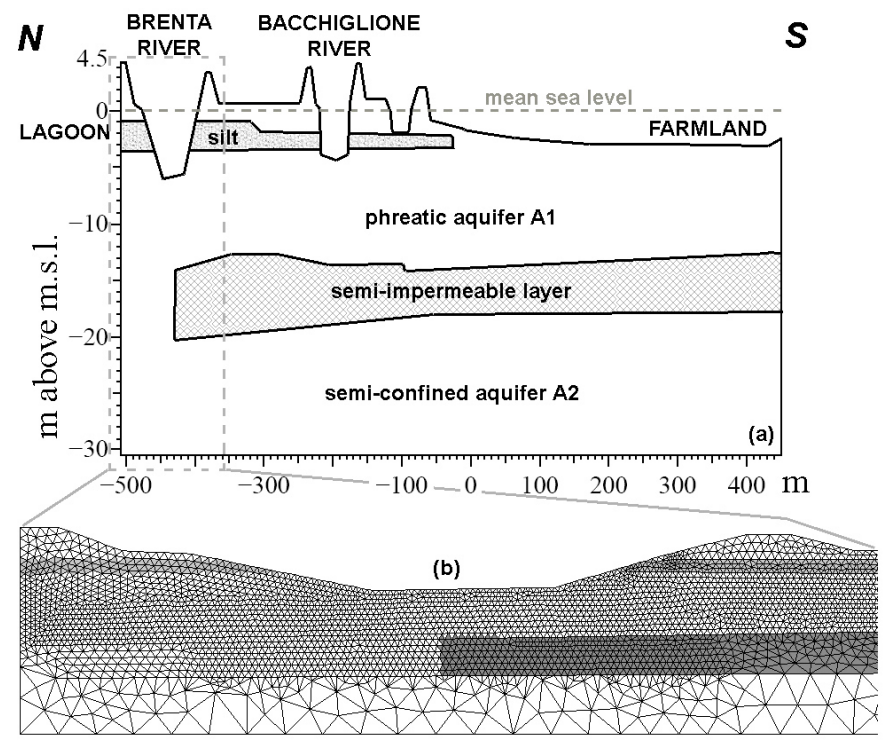

Figure 4: (a) Sketch of the model domain and (b) enlargement of the triangular grid in correspondence of the Brenta river. Vertical exaggeration is 15 in (a), whereas (b) is undistorted.

from the ground surface down to $-30 \mathrm{~m}$ above m.s.l. where the impermeable layer separating the contaminated A2 aquifer from the freshwater A3 sandy unit is located (fig. 2). The section is discretized into a triangular mesh composed of 36748 elements and 19113 nodes, with the smallest elements close to the river beds that are likely to be the major sources of contamination. The COUP_HYB model is designed so as to potentially allow for different flow and transport parameters over each triangular (tetrahedral in a 3D setting) element; for the Casetta simulations only selected hydrogeological parameters were assumed to be spatially variable within a block heterogeneous structure based on the lithostratigraphic sequence of fig. 2. Simulations are run in fully saturated conditions with an isotropic $K_{s}$.

According to available measurements the following values are used: $K_{s \text {, sand }}=3 \times 10^{-4} \mathrm{~m} / \mathrm{s}, K_{s, \text { silt }}=6 \times 10^{-5} \mathrm{~m} / \mathrm{s}$, and $K_{s, \text { clay }}=3 \times 10^{-8} \mathrm{~m} / \mathrm{s}$. The other solute transport parameters are defined as: porosity $\phi=0.20$, elastic storage $S_{s}=1 \times 10^{-3} \mathrm{~m}^{-1}$, density ratio $\varepsilon=0.025$, viscosity ratio $\varepsilon^{\prime}=0.3$, molecular diffusion coefficient $D_{0}=0$, longitudinal $\alpha_{L}$ and transverse dispersivity and $\alpha_{T}$ equal to $1 \times 10^{-1}$ and $1 \times 10^{-3}$, respectively.

\subsection{Numerical results}

We present the results of some preliminary simulations aimed at investigating the effects of the natural factors controlling the dynamics of the saltwater intrusion in the coastal aquifers, i.e. the water level and salt concentration in the 
lagoon, the Brenta and Bacchiglione rivers, and the reclamation channel located south of Bacchiglione.

A zero concentration initial condition is used throughout the domain so as to simulate the expected migration of the saltwater front from the lagoon and river boundaries. Three cases are simulated according to different boundary conditions in terms of both pressure head $\psi$ and normalized salt concentration $c$ :

a. case 1: the water level in the lagoon and the rivers is prescribed at $0 \mathrm{~m}$ above m.s.l.; the groundwater level at the inland boundary at $-4 \mathrm{~m}$ above m.s.l, i.e. $1 \mathrm{~m}$ below the ground surface as maintained by the drainage system. Hydrostatic pressure distribution is prescribed along the vertical boundaries and no recharge occurs from the farmland surface. Relative water concentration is set to 1 in the lagoon with fresh-water within the whole watercourses (fig. 5);

b. case 2: the same as case 1 with the water level in the rivers set at $+0.8 \mathrm{~m}$ above m.s.l. This value is representative of the normal river condition since the simulated section is about $10 \mathrm{~km}$ far from the river mouth (fig. 6);

c. case 3: the same as case 1 with the salt concentration in Brenta and Bacchiglione waters equal to the sea value. This is a typical summer condition when sea water encroaches along the final $15-20 \mathrm{~km}$ of the watercourses (fig. 7).
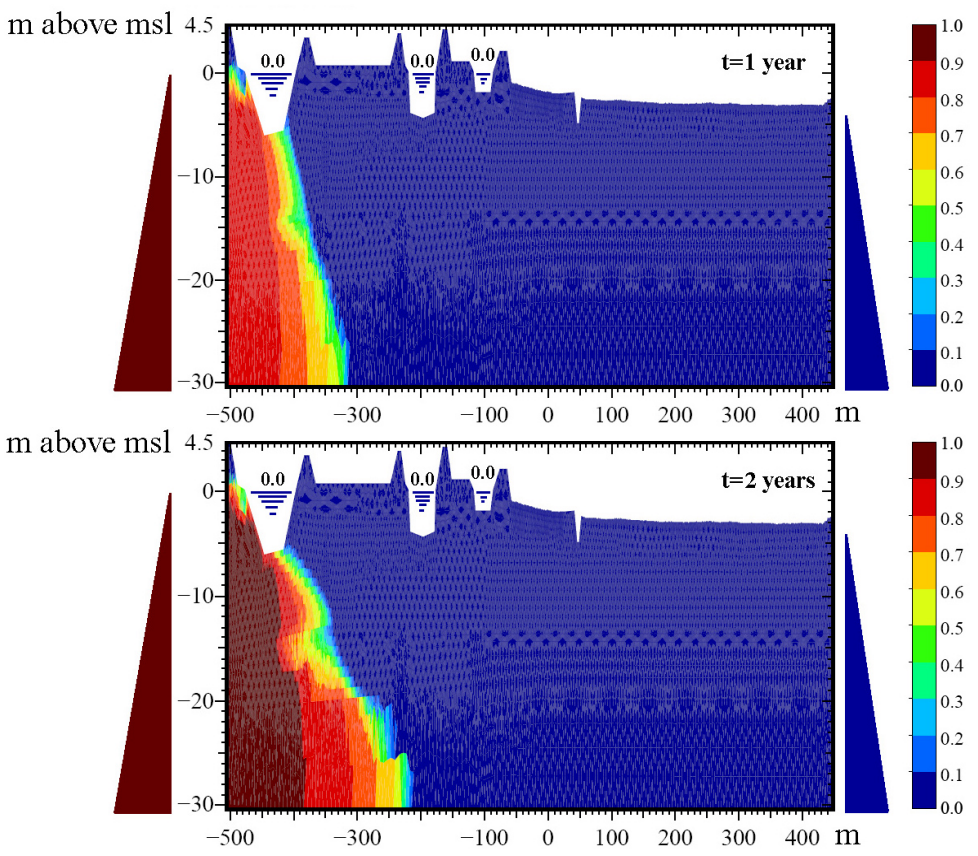

Figure 5: Case 1. Relative concentration as obtained from the COUP_HYB after 1 year (above) and 2 years (below). The boundary conditions are shown. Vertical exaggeration is 15. 
The model results are presented in fig. 5 to fig. 7. The maps of the relative concentration after 1 and 2 years from the beginning of the simulation are shown for each scenario. The main outcome can be summarized as follows:

a. the lagoon is an important source of salt contamination, especially for the semi-confined aquifer (fig. 5), but the water levels in the rivers running parallel to the lagoon boundary are likely to play a fundamental role in controlling the contamination level in the shallow aquifers. A river water level $1 \mathrm{~m}$ higher than the mean sea level suffices to preclude the inland movement of the lagoon salty water (fig. 6);

b. because of their location well above the surrounding farmland, the Brenta and Bacchiglione rivers are the main waterbodies impacting on the groundwater quality. If the two rivers contain seawater, they are a potential source of severe contamination for the aquifers in the surrounding farmland (fig. 7). In fact, the drainage water authority in charge of the area is constructing an alignment of mobile gates at the mouth of the Brenta river to prevent the seawater migration upstream during periods of low river discharge;

c. the drainage/irrigation network represents an important source of freshwater that can act as an important mitigation factor for the shallower portion of the phreatic aquifer (fig. 7).
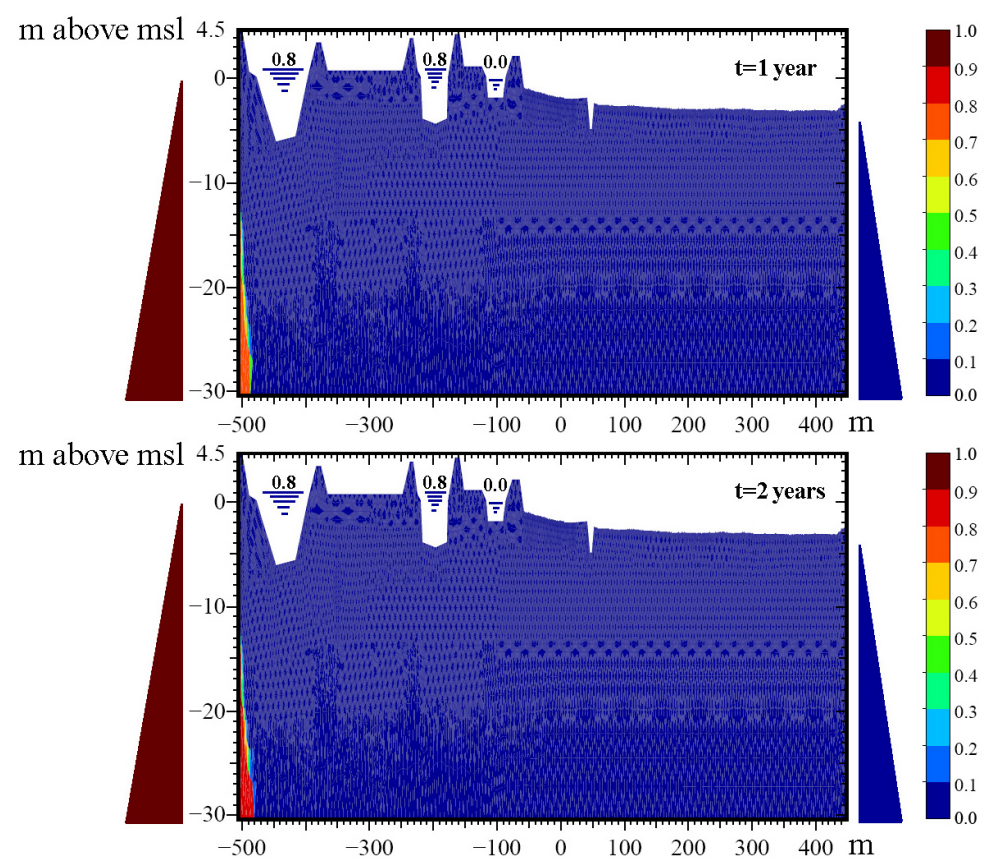

Figure 6: $\quad$ Case 2. Relative concentration obtained by the COUP_HYB after 1 year (above) and 2 years (below). The boundary conditions are shown. Vertical exaggeration is 15 . 

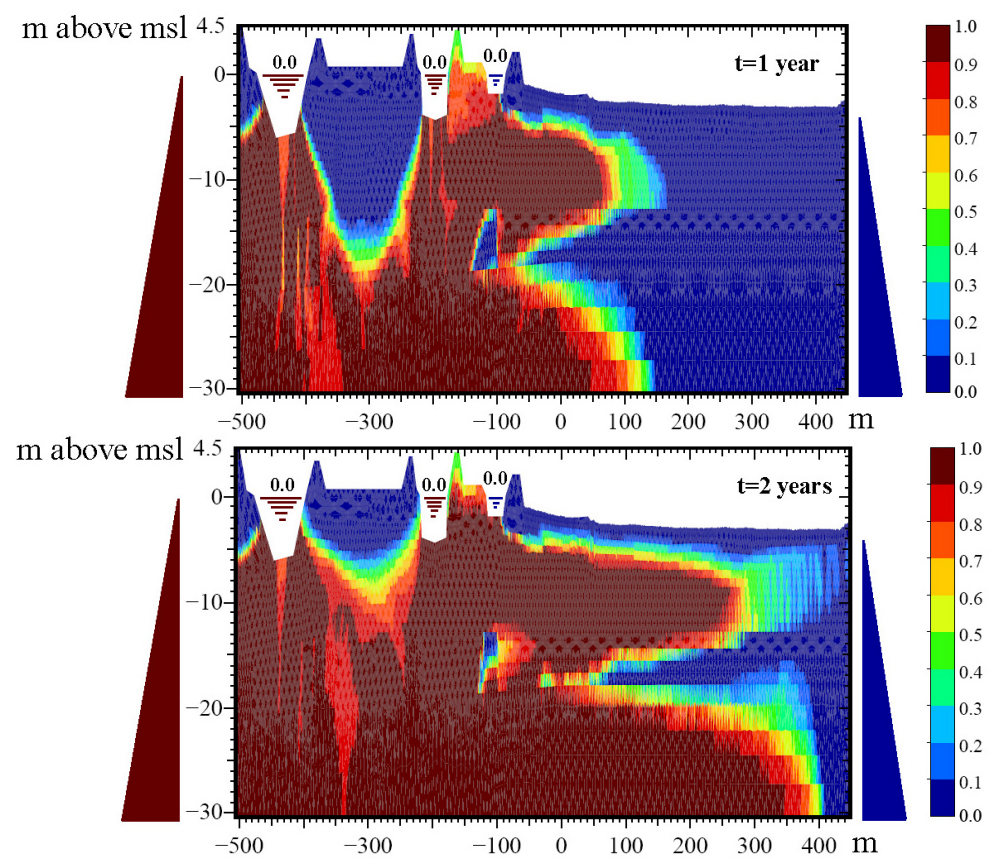

Figure 7: Case 3. Relative concentration obtained by the COUP_HYB after 1 year (above) and 2 years (below). The boundary conditions are shown. Vertical exaggeration is 15.

\section{Conclusions}

The risk of soil desertification and the jeopardizing of agricultural activities are two major issues in the farmland bounding the southern Venice Lagoon, Italy, due to a possible saltwater contamination of the shallowest aquifers.

A coupled density-dependent groundwater flow and transport model has been implemented to simulate the propagation of the contaminant plume along a vertical cross section orthogonal to the lagoon boundary at the Casetta site. A set of preliminary computational analyses allows to define the role played by the lagoon major watercourses. Although the lagoon is an important source of saltwater, it turns out that the rivers exert an important role in improving or worsening the subsurface contamination. The rivers can act indeed as an effective hydraulic barrier to salt contamination from the lagoon if they contain freshwater or, viceversa, can represent a strong source of salinization if seawater encroaches along the final portion of the watercourses.

\section{Acknowledgements}

The work has been partially supported by Co.Ri.La., Subproject 3.10, and by the VECTOR (Action 3 - Research line 5, CLIVEN) project. 


\section{References}

[1] Qahman, K. \& Larabi, A., Evaluation and numerical modeling of seawater intrusion in the Gaza aquifer (Palestine). Hydrogeology J., 14, pp. 713728, 2006.

[2] Pousa, G., et al., Coastal processes and environmental hazards: the Buenos Aires (Argentina) and Venetian (Italy) littorals. Environmental Geology, 51, pp. 1307-1316, 2007.

[3] Paniconi, C., Khlaifi, I., Lecca, G., Giacomelli, A. \& Tarhouni, J., Modeling and analysis of seawater intrusion in the coastal aquifer of Eastern Cap-Bon, Tunisia. Transport in Porous Media, 43, pp. 3-28, 2001.

[4] Church, T.M., An underground route for the water cycle. Nature, 380, pp. 579-580, 1996.

[5] Simmons Jr., G.M., Importance of submarine groundwater discharge (SGWD) and seawater cycling to material flux across sediment/water interfaces in marine environments. Marine Ecology Progress Series, 84, pp. 173-184, 1992.

[6] Carbognin, L., Gambolati, G., Putti, M., Rizzetto, F., Teatini, P. \& Tosi, L., Soil contamination and land subsidence raise concern in the Venice watershed, Italy. Management of Natural Resources, Sustainable Development and Ecological Hazards, eds. C. A. Brebbia et al. eds., WIT Press: pp. 691-700, 2006.

[7] de Franco, R., Biella, G., Tosi, L., Teatini, P., \& Rorai, C., Seasonal oscillations in saltwater intrusion at the Venice Lagoon boundary detected by time-lapse ERT. Coastal Aquifer: Challenges and Solutions - Proc. TIAC-SIACODE 2007, eds. A. Pulido-Bosch et al., Istituto Geologico y Minero de Espana: vol. 1, pp. 275-283, 2007.

[8] de Franco, R., et al., Saltwater intrusion monitoring by time lapse electrical resistivity tomography. J. of Applied Geophysics, 2009. In press.

[9] Rizzetto, F., Tosi, L., Carbognin, L., Bonardi, M., \& Teatini, P., Geomorphological setting and related hydrogeological implications of the coastal plain south of the Venice Lagoon (Italy). Hydrology of the Mediterranean and Semiarid Regions, eds. E. Servat et al., IAHS Publ. n. 278: Wallingford, UK., pp. 463-470, 2003.

[10] Gambolati, G., Putti, M., \& Paniconi, C., Three-dimensional model of coupled density-dependent flow and miscible salt transport in groundwater. Seawater Intrusion in Coastal Aquifers; Concepts, Methods and Practices, eds. J. Bear et al., Kluwer Academic Publishers: Dordrecht, The Netherlands, pp. 315-362, 1999.

[11] Mazzia, A., \& Putti, M., Mixed-finite element and finite volume discretization for heavy brine solutions in groundwater. J. Computational Applied Mathematics, 147, pp. 191-213, 2002.

[12] Mazzia, A., \& Putti, M., Three-dimensional mixed finite element - finite volume approach for the solution of density-dependent flow in porous media. J. Computational Applied Mathematics, 185(1), pp. 347-359, 2006. 